\title{
REAPPRAISAL OF THE ACCESSORY INTERNAL THORACIC ARTERY
}

\author{
Jacomay Aletta Schickerling ${ }^{1}$, Kathleen van Niekerk ${ }^{1}$, Quenton Wessels ${ }^{1}$, Adéle du Plessis ${ }^{1}$ \\ ${ }^{1}$ Department of Anatomy, School of Medicine, University of Namibia, Windhoek, Namibia
}

Correspondence to Dr Quenton Wessels, School of Medicine, Faculty of Health and Medicine University of Namibia, Windhoek Namibia. Email: qwessels@unam.na

\begin{abstract}
The accessory internal thoracic artery (AITA) is a variably large branch of the initial portion of the internal thoracic artery (ITA). The AITA has been neglected as an important anatomical structure and has been identified as the culprit for the "steal-syndrome" of coronary blood flow after the use of the ITA in coronary artery revascularisation. A cadaveric study of 50 cadavers was performed to investigate the occurrence of the AITA. We found $10(20 \%)$ out of the 50 cadavers examined, presented with AITAs either bilaterally $(4 \%)$ or unilaterally $(16 \%)$. Five of the eight unilateral specimens showed a left-sided appearance of the AITA. Fourteen percent of the AITAs were found in cadavers of Mixed-race (Coloured) and $6 \%$ in individuals of African descent. Knowledge of the AITA is essential for any thoracic surgeon, during the preparation of the ITA for coronary revascularisation. Data from this study supports the notion that the AITA is a highly variable structure with little correlates based on ethnicity. The AITA appear to be found more often on the left in unilateral specimens.
\end{abstract}

Key Words: Accessory, Internal Thoracic artery

\section{INTRODUCTION}

The accessory internal thoracic artery (AITA), when present, is a variably large branch of the initial portion of the internal thoracic artery (ITA). This anatomical structure is rarely mention in classical anatomical and surgical texts despite its clinical significance. The AITA is of particular interest when ITA-coronary revascularisation is considered and with the placement of a chest drain (Paraskevas et al., 1990). The AITA was first described by Heister (1730) and its name evolved over time from the lateral costal branch of the inferior mammary artery' (Otto, 1830), the 'lateral internal mammary artery' (Henle, 1876), but no current Terminologia Anatomica reference has been made to date. The authors will subsequently use accessory internal thoracic artery (AITA) throughout the text as it is more anatomically descriptive. The occurrence of the AITA varies greatly but it is a tributary of the ITA (Barberini et al., 2004). Research by Vorster et al. (1998) focused on the variability of the origin of the internal thoracic and vertebral arteries after a cadaver demonstrated abnormal origins for both vessels (Vorster et al., 1998). The study, on a South African cadaver population, was conducted on 60 adult cadavers and measurements were taken to bordering structures. In one subject, the right ITA originated from the third part of the subclavian artery $(0.83 \%)$. It is thus important to note that the ITA can present with some variations when considering the AITA.

The Work by Paraskevas et al. (1990) noted that the AITA is a relatively large branch of the initial part of the ITA, which was found in 4.54 $\%$ of 22 cadavers studied (Paraskevas et al., 1990). The course of this artery usually lies in the inner surface of the anterolateral thoracic wall, and its diameter is sometimes almost equivalent to that of the main trunk of the internal thoracic artery. Research on the occurrence of the AITA in a Taiwanese cadaveric study found that 10 of the 132 
cadavers $(7.58 \%)$ presented with this anatomical structure. The authors also found that the AITA originated from the proximal part of the internal thoracic artery, near its normal origin from the subclavian artery (Namking et al., 2011).

Knowledge of the AITA is essential for any thoracic surgeon, during the preparation of the internal thoracic artery for coronary revascularisation, insertion of a pacemaker, or the placement of thoracic intercostal drain for the management of a pneumothorax or haemothorax. The general safe area, when considering the AITA for surgical procedures, is the fourth intercostal space, at least 3 centimetres anterior to the midaxillary line (Namking et al., 2011). Other considerations include the anastomoses of AITA with the ITA via the intercostal arteries (Vural et al., 2018). The aim here is to revisit the occurrence of the AITA through a cadaveric study and contribute to the existing, yet limited, body of knowledge.

\section{MATERIALS AND METHODS}

The study was conducted during routine dissections of formalin-embalmed adult cadavers, from the Western Cape in South Africa, at the University of Namibia, School of Medicine. The possible presence of 100 AITA arteries from 50 cadavers (36 males and 14 females), whose ages ranged between 25 and 75 were examined. Ethnic demographics of the dissected cadavers included: 9 (18\%) African males and $1(2 \%)$ female, $22(44 \%)$ Mixedrace (Coloured) males and $10(20 \%)$ females, and $5(10 \%)$ Caucasian males and $3(6 \%)$ females. The cadaveric material was handled and processed in accordance with the Anatomical Donations and Post-mortem Ordinance, No. 12 of $1977 . \quad$ All the small branches, rami of the anterior intercostal arteries and thus arising from the internal thoracic artery, were not considered. Measurements of the thickness of the AITAs were made using a calibrated digital calliper.

\section{RESULTS}

The study consisted of 36 (72\%) male and 14 (28\%) female cadavers of various ethnic groups. The occurrence of the AITA was $20 \%$, as it was found in $10(20 \%)$ out of the 50 cadavers examined (Table 1 ). The presence of the AITA was found in 9 of $36(25 \%)$ males and one of the $14(7.14 \%)$ female specimens. In all $10(20 \%)$ of the cadavers, the AITAs were unsegmented, running across the anterior thoracic chest wall. In two (4\%) of the cadavers, the AITA was found bilateral. Three cadavers $(6 \%)$ presented with a unilateral AITA on the right side and five (10\%) cadavers presented the artery on the left side of the anterior thoracic wall (Table 1). Data from our study show that the occurrence of the AITA, based on ethnicity, were primarily observed in the Coloured/Mixed-race cadavers (seven or $14 \%$ ) and secondly, in the cadavers of African descent (three or 6\%). Data from other publications. 

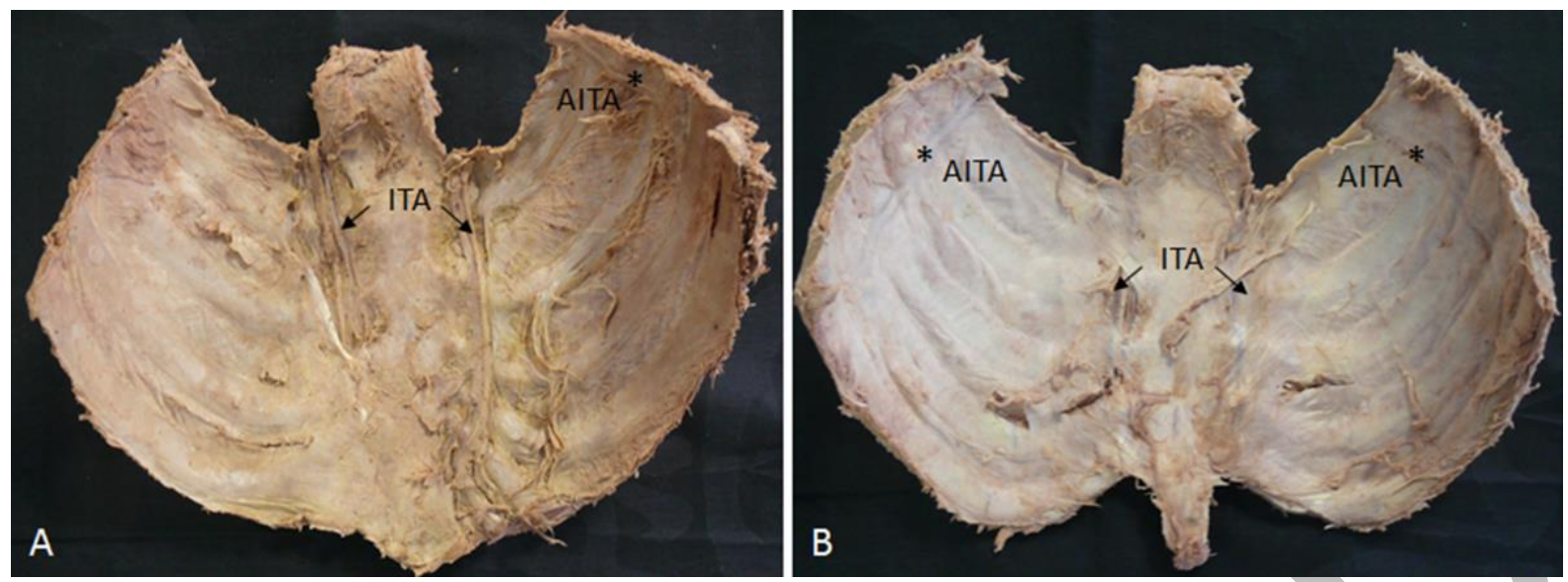

Figure 1. A and B: Dissection of the anterior thoracic wall demonstrating the internal thoracic arteries (ITA) and the accessory internal thoracic arteries (AITA) with a unilateral left-sided AITA (A) and bilateral AITAs (B).

All the AITAs originated from the superior part of the ITA inferior to the subclavian artery, and then ran inferiorly over the midclavicular line, continuing in an inferolateral direction across the anterior thoracic wall. The arteries were found to terminate at proximal to the anterior axillary line, thereafter continuing as an intercostal vessel (Figure 1). The diameters of the AITAs all ranged between $2 \mathrm{~mm}$ to $4 \mathrm{~mm}$ whereas the diameter of ITAs ranged between $2 \mathrm{~mm}$ and $3 \mathrm{~mm}$ in diameter. It is worth noting that these measurements are of academic interest as there are tissue shrinkage associated with the embalming process and exposure to air in the practical dissection laboratory.

Table 1. The occurrence of the accessory internal thoracic artery (AITA).

\begin{tabular}{|l|l|}
\hline Number of cadavers with AITA & $10(20 \%)$ \\
\hline Bilateral & $2(4 \%)$ \\
\hline Unilateral & $8(16 \%)$ \\
\hline Right & 3 \\
\hline Left & 5 \\
\hline Total Examined & 50 \\
\hline
\end{tabular}

$\mathrm{N}=$ Number of cadavers

Table 2. The incidences of the accessory internal thoracic artery (AITA), otherwise known as the lateral costal branch in previous studies.

\begin{tabular}{|l|l|l|l|}
\hline Citation & $\begin{array}{c}\text { Number of } \\
\text { cases/sample size } \\
\text { and occurrence (\%) }\end{array}$ & $\begin{array}{c}\text { Unilateral } \\
\text { occurrence (\%) }\end{array}$ & $\begin{array}{c}\text { Bilateral } \\
\text { occurrence } \\
\text { (\%) }\end{array}$ \\
\hline Bean, 1905 & $5 / 28(18.0)$ & unspecified (?) & unspecified (?) \\
\hline DeGaris, 1924 & $22 / 139(15.8)$ & $17(12.2)$ & $5(3.6)$ \\
\hline Adachi, 1929 & $16 / 86(18.6)$ & $13(15.1)$ & $3(3.5)$ \\
\hline Alexander, 1946 & $9 / 51(18.0)$ & $5(9.8)$ & $4(7.8)$ \\
\hline Kropp, 1951 & $31 / 112(27.6)$ & $25(22.3)$ & $6(5.4)$ \\
\hline Yokota, 1961 & $15 / 150(10.0)$ & unspecified (?) & unspecified (?) \\
\hline Nathan et al., 1982 & $10 / 60(16.6)$ & $7(11.6)$ & $3(5.0)$ \\
\hline Henriquez et al., 1993 and 1997 & $15 / 90(16.6)$ & $10(11.1)$ & $5(5.6)$ \\
\hline Sutherland and Desai, 2000 & $31 / 103(30.1)$ & $6(5.8)$ & $25(24.3)$ \\
\hline Paraskevas et al., 2010 & $2 / 22(4.5)$ & unspecified (?) & unspecified (?) \\
\hline Namking et al., 2011 & $10 / 132(7.6)$ & $6(4.6)$ & $4(3.0)$ \\
\hline
\end{tabular}




\begin{tabular}{|l|l|l|l|}
\hline Vural et al., 2018 & unspecified & unspecified (11.1) & unspecified (5.5) \\
\hline
\end{tabular}

\section{DISCUSSION}

This study investigated the occurrence of the AITA in a cadaveric population. Our findings point towards a high occurrence (20\%) compared to previous findings: $18 \%$ (Bean, 1905), 15.8\% (DeGaris, 1924), 18.6\% (Adachi, 1929), $18.0 \%$ (Alexander, 1946), 27.6\% (Kropp, 1951), 10.05 (Yokota, 1961), and more recently $7.6 \%$ (Namking et al., 2011) (Table 2). We found, when present, the AITA was a tributary of the ITA and originated close to the origin of the ITA. These findings point towards the variability of this anatomical structure. These findings correspond to that of others (Adachi, 1929; Henriquez et al., 1993).

Our findings further demonstrate a variability of the occurrence of the AITA based on ethnicity. Work done by DeGaris (1924) found that the AITA occurred in $17 \%$ of the cadavers of African descent compared to a lower $5 \%$ for a Caucasian cadaver population (DeGaris, 1924). Others found an incidence of $27.6 \%$ in a Caucasian sample $(n=112)$ and $17.8 \%$ $(n=28)$ in a Mixed-race cadaver population (Bean, 1905; Kropp, 1951) (Table 2). Previous studies cited here have not focussed on the occurrence of the AITA based on ethnicity or used a cadaver/patient population with a single ethnic origin (Adachi, 1929; Henriquez et al., 1993 and 1997). Once again, the occurrence based on ethnicity appear to be highly variable. This variability should be considered, when opting to employ the ITA as an option in coronary revascularisation.
Of interest is that the work of Adachi (1929) and Kropp (1951) points towards a left-sided dominance in the incidence of the AITA when presenting unilaterally. Our findings support this left-sided dominance, despite our small sample size (Adachi, 1929; Kropp, 1951). A limitation of the current study is its sample size of 50 but the authors feel that this compares relatively well with the work of others (Alexander, 1946; Natahn eta al., 1982; Paraskevas, 2010). We hope this the work presented here would encourage others to expand on the existing, yet limited body of knowledge on the AITA.

The AITA has been neglected as an important anatomical structure and has been identified as the culprit for the "steal-syndrome" of coronary blood flow after the use of the ITA in coronary artery revascularisation. This is due to the anastomosis between the ITA and the AITA via the lateral intercostal arteries (Vural et al., 2018).

In conclusion, data from this study supports the notion that the AITA is a highly variable structure with little correlates based on ethnicity but appear to found more often on the left in unilateral specimens. Through this study, we hope to add to the growing body of knowledge on the AITA and further highlight its importance in ITA-coronary artery bypass surgery or other surgical interventions entailing the anterior thoracic wall.

\section{REFERENCES}

1. Adachi B. 1928. Das Arteriensystem der Japaner, vol. 1. Kyoto: Verlag der KaiserlichJapanischen Universita"t. p 159-160.

2. Alexander WF. 1946. The course and incidence of the lateral costal branch of the internal mammary artery. Anat Rec 94:446.

3. Barberini F, Cavallini A, Carpino G, Correr S, Brunone F. 2004. Lateral costal artery: accessory thoracic vessel of clinical interest. Clin Anat 17(3): 218-226.

4. Bean R. 1905. A composite study of the subclavian artery in man. Am J Anat 4:303-328.

5. DeGaris CF. 1924. Patterns of branching of the subclavian artery in White and Negro stocks. Am J Phys Anthrop 7:95-107.

6. Heister (1730) Cited from Henle (1876) 
7. Henle J. 1876. Handbuch der systematischen Anatomie des Menschen, Band III, Abt. I, Aufl. II. Friedrich Vieweg und Sohn, Braunschweig. p 262-263.

8. Henriquez JA, Mandiola EA, Prates JC. 1993. Lateral costal branch of the internal thoracic artery. Clin Anat 6(5):295-299.

9. Henriquez-Pino JA, Gomes WJ, Prates JC, Buffolo E. 1997. Surgical anatomy of the internal thoracic artery. Ann Thorac Surg 64(4):1041-1045.

10. Kropp BN. 1951. The lateral costal branch of the internal mammary artery. J Thorac Surg 21(4):421-425.

11. Namking M, Woraputtaporn W, Suarchawaratna S, Chaijaroonkhanarak W, Khamanarong K. 2011. Incidence of the accessory internal thoracic artery and its safety area in the thoracic wall. J Med Assoc Thai 94(12):1500-1503.

12. Nathan H, Rubinstein Z, Bogart B.1982. Accessory internal thoracic artery. Anatomia Clinica 3(4): 333-337.

13. Otto AW. 1830. Lehrbuch der pathologischen Anatomie des Menschen und der Thiere. August Rücker, Berlin.

14. Paraskevas G, Papaziogas B, Natsis K, Ioannidis O, Martoglou S, Economou D, Kitsoulis P. 2010. Accessory internal thoracic artery and its clinical significance. Chirurgia 105:709-11.

15. Sutherland FWH, JB Desai. 2000. Incidence and size of the lateral costal artery in 103 patients. Ann Thorac Surg 69:1865-1866.

16. Vorster W, Du Plooy PT, Meiring JH. 1998. Abnormal Origin of Internal Thoracic and Vertebral Arteries, Clin Anat 11:33-37.

17. Vural U, Aglar AA, Kizilay M, Balci AY, Kayacioglu I. 2018. Lateral costal artery: clinical importance of an accessory thoracic artery. Am J Cardiol 121(8):e117.

18. Yokota M. 1961. Stereoroentgenographical studies on the internal mammary artery of the Japanese foetus. J Tokyo Med COIL 19:657-676. 